\title{
Proksimal humerus kaynamamaları
}

\author{
Non-unions of the proximal humerus
}

\author{
Onur Tunalı ${ }^{1}$, Ata Can Atalar ${ }^{1,2}$ \\ ${ }^{1}$ Acıbadem Maslak Hastanesi, Ortopedi ve Travmatoloji Bölümü, İstanbul \\ ${ }^{2}$ Acıbadem Üniversitesi Tıp Fakültesi, Ortopedi ve Travmatoloji Anabilim Dalı, İstanbul
}

Proksimal humerus kırıkları, özellikle 65 yaş üstünde en sık görülen kırıklardan biridir. Yaşlı popülasyonun artmasına bağlı olarak bu tip kırıkların görülme sıklığının ve kaynamama gibi komplikasyonlarının artması beklenmektedir. Kaynamama oranı literatürde \%1-20 arasında bildirilmiştir. Kaynamama görülen hastalarda ciddi fonksiyonel kısıtlılık ve ağrı görülmektedir. Kaynamama için risk faktörleri olarak kırık tipi, deplasmanı, medial kalkarın bozulması, redüksiyon yetersizliği, yetersiz tespit, hastaya bağlı nedenler (sigara, steroid kullanımı, romatoid artrit) gibi birçok faktör bildirilmiştir. Kaynamama tedavisinde uygulanacak yöntem, hastanın kemik stok miktarına, kemik kalitesine, atrofinin tipine, başın canlılığına, rotator manşetin ve tüberküllerin durumuna göre belirlenir. Kemik kalitesinin iyi olduğu, yeterli kemik stoğunun bulunduğu olgularda ilk tercih açık redüksiyon, plak vida ile tespit ve grefonaj olmaktadır. Bu yöntemle yüksek kaynama oranları ve başarılı fonksiyonel sonuçlar elde edilmiştir. Kemik stoğun yetersiz olduğu, başın canlılığını kaybettiği durumlarda artroplasti tercih edilmektedir. Artroplasti sonuçlarında tüberküllerin anatomik tespiti ve kaynaması fonksiyonlar üzerinde en etkili faktördür. Rotator manşet patolojisi olanlar ve tüberkül malpozisyonu bulunan hastalarda ters omuz protezi tercih edilmektedir. Artroplasti yöntemi ile ağrı palyasyonu çok iyi sağlanmakla beraber fonksiyonel sonuçlar primer artroplastilere göre kötü tespit edilmiştir ve dislokasyon oranı daha fazladır. Tedavi planlanmadan önce, hasta gerek klinik gerekse radyolojik olarak çok iyi değerlendirilmeli ve o hastaya uygun tedavi yöntemi belirlenmelidir. Mümkün olan durumlarda, öncelikle osteosentez yöntemi tercih edilmelidir.

Anahtar sözcükler: kaynamama; proksimal humerus; osteosentez; artroplasti; grefonaj
Proximal humerus fractures are one of the most frequent fractures especially in over 65 years of age. Due to the increase in geriatric population, also an increase is expected in the prevalence of these fractures and it's complications like non-union. Non-union prevalence was reported between $1-20 \%$ in the literature. The patients with non-union have severe pain and functional limitations. Fracture type, displacement, medial calcar disruption, non-anatomical reduction, inadequate fixation, factors related to patient (smoking, steroid usage, romatoid arthritis) are the risk factors for non-union. The treatment method is determined according to patient's bone stock, bone quality, type of the atrophy, vitality of the humeral head, integrity of the rotator cuff, and the tubercules. Open reduction, plate fixation, and bone grafting is preferred in patients who had good bone stock and quality. High rate of union and good functional results were reported with this method. If the patient has poor bone stock or avascular necrosis of the head arthroplasty is performed. Anatomic fixation and the union of the tubercules is the most important factor for good functional results. The reverse total shoulder arthroplasty is preferred in patients with rotator cuff deficiency or tubercule malposition. Pain relief can be achieved successfully with arthroplasty but functional results were not improved as much as primary arthroplasty, and dislocation rates were high. The patient should be evaluated clinically and radiologically very carefully, then the treatment method, which was suitable for that patient, should be determined. If possible, osteosynthesis method should be considered initially.

Key words: non-union; proximal humerus; osteosynthesis; arthroplasty; bone grafting
P roksimal humerus kırıkları bütün kırıkların yaklaşık olarak \%4-5'ini oluşturur. ${ }^{[1]}$ Proksimal humerus kırıklarının büyük bir çoğunluğu (\%8085) minimal deplase veya non-deplase kırıklar oluşturmakta ve konservatif tedavi ile başarılı sonuçlar elde edilmektedir. ${ }^{[2]}$ Kabul edilebilir sınırlar dışında deplasmanı olan kırıklar ise cerrahi olarak tedavi edilmektedir. Proksimal humerus kırıklarında perkütan pinleme, plak vida ile osteosentez, intramedüller çivi ile osteosentez gibi birçok cerrahi seçenek bulunmaktadır.

- İletişim adresi: Dr. Ata Can Atalar, Acıbadem Maslak Hastanesi Ortopedi ve Travmatoloji Bölümü, Darüşşafaka Mahallesi, Büyükdere Cad. No:40, 34457, Sarıer, İstanbul Tel: 0212 - 3043640 e-posta: atacan.atalar@acibadem.edu.tr

- Geliș tarihi: 1 Kasım 2017 Kabul tarihi: 1 Kasım 2017 
Gerek konservatif gerek cerrahi tedavi sonrası başarılı sonuçlar bildirilmiştir. ${ }^{[3-5]}$ Yaşlı popülasyonun artmasına bağlı proksimal humerus kırıklarının görülme sıklığı da artmaktadır. ${ }^{[6]}$ Altmış beş yaş üstünde en sık görülen 3. kırıktır. ${ }^{[7]}$ Görülme sıklığının artmasına bağı olarak gelecek yıllarda kaynamama gibi komplikasyonların da daha sık ortaya çıkacağı aşikardır.

Proksimal humerus kırıklarında kaynamama sıklığı çok değişik oranlarda bildirilmiştir. Literatürde kaynamama sıklığı \%20 olarak bildirilmiş ve kaynamamanın ana nedeni olarak konservatif tedavi gösterilmiştir. ${ }^{[8]}$ Neer ise 117 üç ve dört parçalı proksimal humerus kırı̆gnda \%13,7 kaynamama bildirmiştir. ${ }^{[9]}$ Court-Brown ve ark., takip ettikleri 1027 proksimal humerus kırığında kaynamama oranını \%1,1 olarak bildirmiştir. Kaynamama, konservatif takip edilenlerde $\% 0,8$ iken cerrahi yapılan grupta $\% 3,4$ oranında görülmüştür. Neer'e göre, deplase kırıklarda kaynamama \%1,7 iken non-deplase kırıklarda \%0,4 olarak bildirilmiştir. Metafizyel parçalanma olan kırıklarda kaynamama oranının \%8'e, \%33-100 translasyonu olan cerrahi boyun kırıklarında ise \%10'a çıktığı bildirilmiştir. ${ }^{[10]}$ Hanson ve ark. konservatif takip ettikleri 160 hastada \% $7^{[11]}$, Clavert ve ark. ise plak vida ile osteosentez yaptıkları 73 hastada \%5,5 kaynamama bildirmişlerdir. ${ }^{[12]}$

\section{RISK FAKTÖRLERi}

Proksimal humerus kırıklarında kaynamamaya etkili birçok faktör ortaya konmuştur. Kırığın şekli, deplasmanı, metafizyel parçalanma, mediyal desteğin sağlanamaması, başı besleyen damarların yaralanması, yumuşak doku interpozisyonu, hastaya bağlı faktörler (sigara, alkol, steroid kullanımı, glenohumeral artrit, romatoid artrit, yaş, osteoporoz), anatomik redüksiyonun sağlanamaması, yetersiz tespit, kalkar vidasının gönderilmemesi veya uygunsuz yerleşimi, agresif rehabilitasyon, hasta uyumsuzluğu kaynamamada etkilidir. Metafizyel parçalanma ve \%33-100 translasyon olan kırıklarda kaynamamanın daha sık olduğu bildirilmiştir. ${ }^{[10]}$ İki parçalı cerrahi boyun kırıkları, kaynamama ile ilişkili en sık görülen kırık paternidir. ${ }^{[13-15]}$ Rotator manşet, biseps tendonu veya sinoviyal sıvının kırık hattına girmesinin kaynamamaya neden olduğu bildirilmiştir. ${ }^{[16,17]}$ Jung ve ark. plak vida ile osteosentez yapılan 63 hastada, mediyal desteğin sağlanamadığı durumda komplikasyon oranlarının yükseldiğini ve kaynamama görülen iki hastada da mediyal desteğin sağlanamadığını belirtmişlerdir. ${ }^{[18]}$ Konservatif takip edilen hastalardan sigara içenlerde kaynamama 5,5 kat fazla görülmüştür. ${ }^{[11]}$ Glenohumeral artriti veya romatoid artriti olan ve konservatif takip edilen hastalarda kaynamamanın iki kat daha fazla olduğu ve bu durumun eklem hareketindeki kısıtlılıktan dolayı kırık hattına binen yüklerin artmasından kaynaklandığı belirtilmiştir. ${ }^{[19]}$ Court-Brown ve ark., takip ettikleri 1027 hastada kaynamama gözükenlerin yaş ortalamasının kaynama gözükenlerden daha fazla olduğunu ve yaşın kaynama üzerinde etkili olduğunu belirtmişlerdir. Plak vida ile osteosentez yapılan hastalarda yapılan çalışmalarda, redüksiyonun kalitesinin iyi olması, kalkar vidasının kullanımının ve uygun yerleştirilmesinin (kalkar mesafesi $\leq 12 \mathrm{~mm}$ ve kalkar oranının $\leq \% 25$ olması) komplikasyon oranlarını azalttığı gösterilmiştir.[20,21]

\section{HASTANIN DEĞERLENDIRILMESi}

Kaynamama gelişen hastalarda ağrı ve omuz fonksiyonlarında ciddi kısıtlılık görülmektedir. Fizik muayenede, hareket kısıtlılı̆gna ek olarak deltoid ve periskapular atrofi görülebilir. Aksiller sinirin fonksiyonu tedavi yöntemine karar vermeden önce mutlaka değerlendirilmeli, şüphe durumunda gerekirse elektromiyelogram yapılmalıdır.

\section{Kaynamama tanısı için ne kadar zaman geçmeli?}

Konservatif takip edilen hastalarda köprü kallus oluşumunun görülmesi için geçen süre ortalama 13 haftadır. ${ }^{[22]}$ Bir başka çalışmada ise, 306 proksimal humerus kırığında ortalama kaynama süresi 100 gün olarak bulunmuştur. ${ }^{[23]}$ Literatürde bu konu üzerinde bir konsensus yoktur. Bazı çalışmalarda kaynamama süresi üç ay alınırken ${ }^{[10,16]}$, bazı yazarlar da bu süreyi altı ay olarak kabul etmişlerdir. ${ }^{[2]}$ Cadet ve ark. ise, 6-8 hafta ara ile çekilen iki grafide kaynama yönünde herhangi bir ilerleme görülmemesini de kaynamama olarak tanımlamışlardır.

Kaynamama düşünülen hastalarda görüntüleme olarak nötralde, iç rotasyonda ve dış rotasyonda gerçek AP grafileri, aksiller ve outlet grafileri çekilmelidir. Grafiler ile kaynamama tanısının konulamadığı şüpheli durumlarda, tüberküllerin pozisyonunu belirlemede ve kemik kaybını değerlendirmede bilgisayarlı tomografi kullanılmalıdır. Rotator manşetin bütünlüğünü ve humerus başının canlılığını değerlendirmek için manyetik rezonans görüntülemeden yararlanılabilir.

Tedavi planını belirlemeden önce, kaynamamanın atrofik mi, hipertrofik mi olduğu belirlenmelidir. Hipertrofik kaynamamalarda temel problem stabilitenin yetersizliği, atrofik kaynamamalarda ise vaskülaritenin ve biyolojinin yetersizliğidir. Tedavi planı temel probleme göre belirlenmelidir. Daha önce opere olan hastalarda tedaviye başlanmadan önce enfeksiyon mutlaka dışlanmalıdır. Enfeksiyon belirteçleri ameliyat öncesinde değerlendirilmeli, ultrasonografi altında psödoartroz sahasından kültür gönderilmelidir. 
Kaynamamada tedavi mümkün olduğunca geciktirilmemelidir. Zaman uzadıkça kemik kalitesinde azalma ve rezorpsiyon artacak, kapsüloligamentöz ve miyotendinöz retraksiyon artacak, proksimal fragmanda kavitasyon oluşacaktır. Bu gibi lokal problemler yapılacak cerrahiyi zorlaştıracaktır. ${ }^{[16,17,25]}$

\section{PROKSIMAL HUMERUS KAYNAMAMA SINIFLANDIRMASI}

Checcia ve ark. 2000 yılında, proksimal humerus kaynamamalarını dört grupta sınıflandırmışlardır. ${ }^{[16]}$

\section{Grup: Yüksek, iki parçalı kaynamama}

Proksimal parçanın küçük olduğu anatomik boyun kırıklarını içerir. Tüberküllerden birinin sağlam olduğu ve $5 \mathrm{~mm}$ 'den az deplasman olan üç parçalı kırıklar da bu gruptadır. Proksimal parçanın küçük olması, başın altındaki spongiyöz kemikte hızlı rezorpsiyon sonrasında kavitasyon oluşması, internal tespit ile tedaviyi zorlaştırır. Bu tip kırıklarda artroplasti seçeneği düşünülmelidir. ${ }^{[26]}$

\section{Grup: Alçak, iki parçalı kaynamama}

Kaynamama tüberkulum minus ile pektoralis major tendonunun yapışma yeri arasında görülür. Proksimal parça 1. gruba göre daha büyüktür ve kemik kalitesi daha iyidir. Tüberküllerden birinin sağlam olduğu 5 mm'den az deplasmanı olan üç parçalı kırıklar da bu grupta yer alır.

\section{Grup: Kompleks kaynamama}

Tüberküllerin $5 \mathrm{~mm}$ 'den fazla deplase olduğu üç ve dört parçalı kırıklar, baş split kırıklar bu grupta yer almaktadır. Tüberküllerin kaynamamış olması veya yanlış pozisyonda kaynamış olması tedaviyi daha da zorlaştırmaktadır.

\section{Grup: Kayıp parçalı kaynamama}

Yüksek enerjili travma, açık kırık veya posttravmatik osteomiyelit sonrası görülen kemik kaybının olduğu kırıklardır.

\section{TEDAVI SEÇENEKLERi}

\section{Konservatif Tedavi}

Ağrısı hafif veya hiç olmayan ve tatmin edici hareket açıklığı ve fonksiyonu olan hastalarda konservatif takip önerilebilir. Medikal hastalıklarından dolayı cerrahi için ciddi risk oluşturan hastalar, ya da cerrahi sonrası rehabilitasyona ve uyarılara uymayacak hastalarda konservatif takip edilebilir. ${ }^{[22]}$ Deltoid fonksiyonu olmayan hastalar da cerrahi tedavi için görece kontrendikasyon oluşturur, çünkü yapılacak cerrahi fonksiyonel olmayacaktır. ${ }^{[26]}$

\section{Cerrahi Tedavi}

\section{Osteosentez}

Kemik kalitesinin iyi olan, humerus başının canlııığını koruduğu, ciddi osteopenisi olmayan ve mediyal kalkarda ciddi parçalanması olmayan hastalarda osteosentez düşünülür. Tüberküllerin bütünlüğü ve fonksiyonelliği ile rotator manşetin fonksiyonelliği de osteosentez kararını belirleyen faktörlerdendir. Osteosentez için kilitli plaklar, kama plaklar, T plaklar, intramedüller çivi gibi birçok yöntem kullanılmıştır. Kama plaklar ve sabit açılı kilitli plakların osteoporotik kemikte biyomekanik olarak stabil bir yapı oluşturduğu belirtilmiştir (Şekil 1). ${ }^{[22]}$

Cerrahi sırasında kaynamama alanı ortaya konmalı, fibröz kaynama dokusu ve psödokapsül eksize edilmelidir. Canlı olmayan kemik dokular çıkarılmalıdır. Ancak, yumuşak dokuların ve periostun aşıı sıyrılmasından kaçınılmalı kemik parçaları devitalize hale getirilmemelidir. Kemik uçlarının kanlandığı görülmeli ve medüller kanal mutlaka açılmalıdır.

Stabiliteye ve biyolojiye destek olmak amacıyla otolog veya allogreft kullanımı da önerilmiştir. Otogreft olarak iliak kanattan gerek kortikal gerek kansellöz kemik grefti sağlanabilir. Ancak, donör saha morbiditesi (ağrı, hematom, kırık) akılda bulundurulmalıdır. Bir başka otolog kemik grefti alma yöntemi de intramedüller kanal oyma yöntemidir. ${ }^{[27,28]}$ Daha büyük miktarda greft gerektiğinde bu yöntem kullanılabilir. Iliak kanata göre donör saha morbiditesi daha azdır ve daha fazla otolog kemik grefti ve pluripotent mezenkimal kök hücre sağlamaktadır. ${ }^{[29]}$ Mekanik desteğin yanında belirgin biyolojik destek gereksinimi olan olgularda vaskülarize fibula grefti de kullanılabilir.

\section{Artroplasti}

Kemik kalitesinin kötü olduğu, proksimal parçada kavitasyon olan (1. grup kaynamama), humerus başının avasküler olduğu ve stabil tespitin sağlanamadığı durumlarda hemiartroplasti seçeneği düşünülmelidir. Tüberküllerin bütünlüğü ve anatomik pozisyonunu koruması, rotator manşetin fonksiyonelliğini koruması, hemiartroplastinin fonksiyonel sonuçlarının iyi olması için olmazsa olmaz koşullardır. Glenohumeral artriti bulunan ve rotator manşeti çalışan hastalarda ise total omuz artroplastisi tercih edilir. Rotator manşeti non-fonksiyonel olan yaşlı hastalarda son yıllarda, ters omuz artroplasti kullanılmaktadır. Kaynamama nedeniyle yapılan artroplastiler sonrası ağrıda belirgin azalma sağlanmakla beraber, fonksiyonel düzelme beklendiği kadar olmamaktadır. ${ }^{[14,15]}$ Fonksiyonel sonuçlar, primer endikasyonla yapılan artroplastilere 

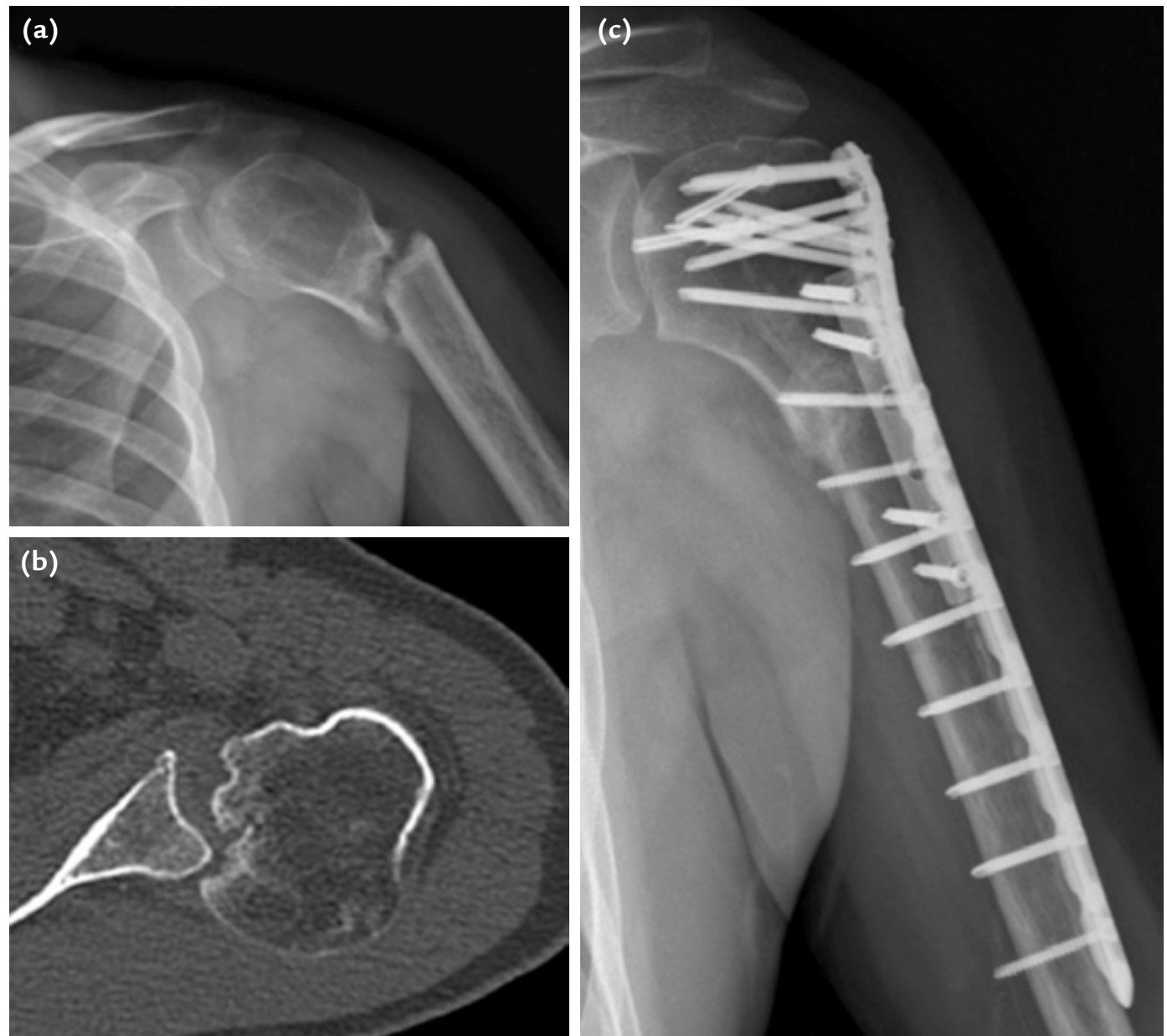

Şekil 1. a-c. Konservatif takip sonrası 6. ay grafisi (a). Kaynamama ile beraber posterior çıkık mevcut (b). Anatomik sabit açılı kilitli plak ve anterior plakla beraber iliak kanattan otogrefonaj sonrası 3. ay grafisi (c).

göre daha kötüdür ve komplikasyon riski daha fazladır (Şekil 2). ${ }^{[26]}$

\section{TEDAVI SONUÇLARI}

Healy ve ark. 1990 yılında, 25 proksimal humerus kaynamama hastasında dört tedavi yöntemi uygulamışlardır. Fleksibl i.m. çivi kullanılan beş hastada da kötü sonuç almışken, $T$ plak ile osteosentez ve grefonaj yapılan 13 hastanın 12'sinde kaynamayı sağlamışlardır. Artroplasti yapılan altı hastanın üçünde iyi fonksiyonel sonuç elde etmişler, ancak ortalama öne fleksiyon derecesi $72^{\circ}$ bulunmuştur. Hastaların tamamı değerlendirildiğinde, yarısından azında iyi sonuç elde etmişlerdir. ${ }^{[15]}$

1996 yilında Duralde ve ark., 20 hastanın yarısında internal tespit ve greftleme, diğer yarısında da hemiartroplasti uygulamıştır. Hastaların yalnızca \%55'inde tatmin edici sonuca ulaşmışlardır. On bir hastanın tekrar opere olması gerekmiş ve internal tespit yapılan hastalarda reoperasyon oranı daha yüksek bulunmuştur. ${ }^{[17]}$

Aynı yıl Walch ve ark., 20 hastada intramedüller trikortikal greft, T plak ile osteosentez ve kaynamama bölgesinin kansellöz otogrefti yöntemi ile \%96 kaynama elde etmişlerdir. Hastaların ortalama öne fleksiyonu $131^{\circ}$ bulunmuş ve hastaların yalnızca \%5'inde tatmin edici olmayan sonuç elde edilmiştir. ${ }^{[30]}$

Ring ve ark. 2001 yılındaki çalışmalarında, kamalı plak ve otogreft ile osteosentez yaptıkları 25 kaynamama hastasının 23'ünde (\%92) kaynama bildirmişlerdir. Hastaların \%80'inde iyi ve mükemmel fonksiyonel sonuç elde edilmiştir. ${ }^{[31]}$

Lin ve ark. 2003 yılında, kilitli intramedüller çivi ve grefonaj uyguladıkları 15 hastanın 14'ünde kaynama elde ettiklerini bildirmişlerdir. Kaynama sağlanan 

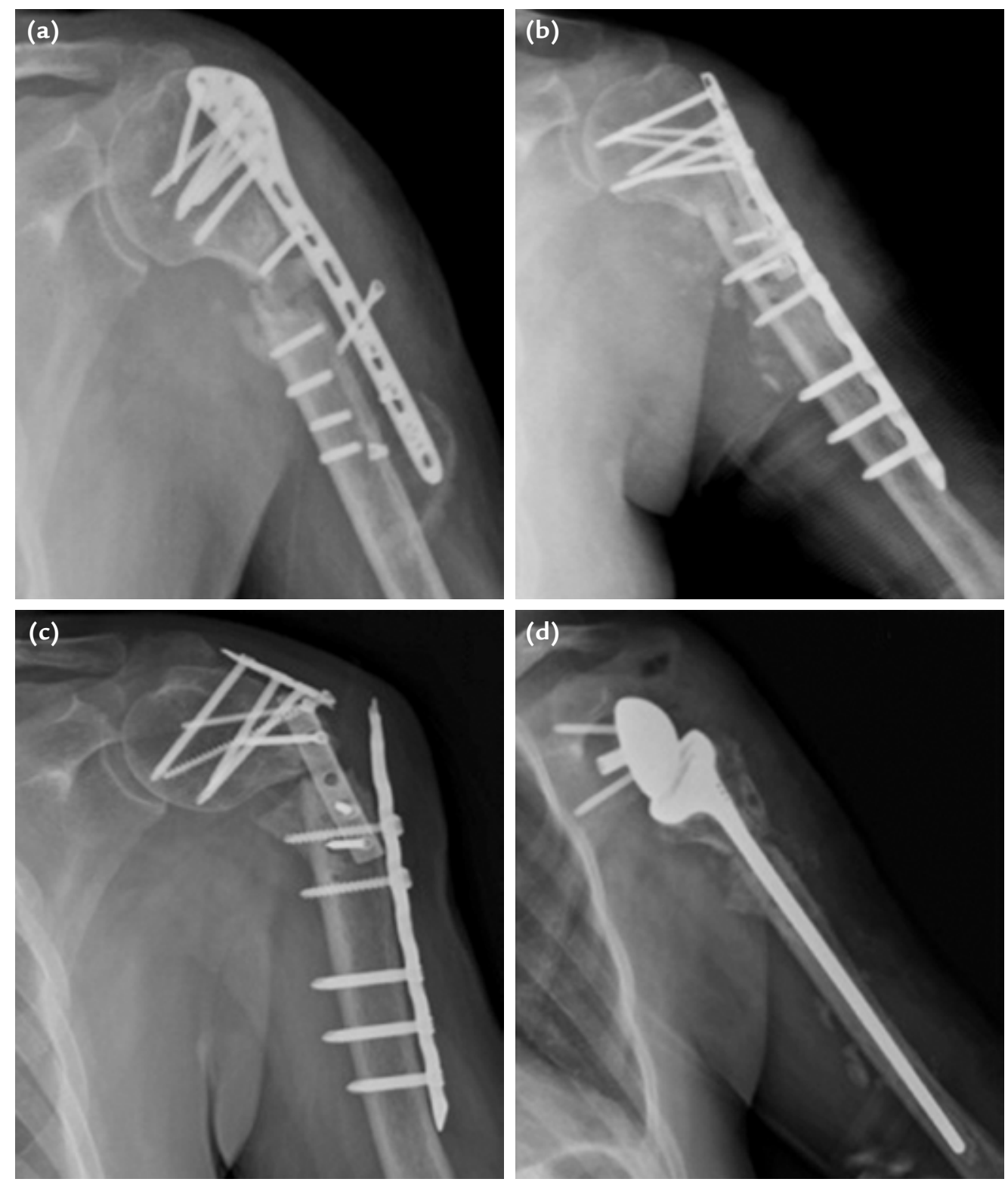

Resim 2. a-d. Plak vida ile osteosentez sonrası kaynamama (a). Açık redüksiyon iliak kanattan otogrefonaj ve öift plak ile osteosentez ameliyatı (b). On bir ay sonra tekrar kaynamama sonrası plak kırılması (c). İkinci revizyon olarak çimentolu ters omuz protezi ve humerus başından otogrefonaj (d).

hastaların ortalama öne fleksiyon derecesi $152,3^{\circ}$ olarak bildirilmiştir. On beş hastanın 13'ünde iyi veya mükemmel sonuç elde etmişlerdir. ${ }^{[32]}$

2004 yılında Galatz ve ark., plak (T plak veya kamalı plak) ile osteosentez ve otogrefonaj yaptıkları 13 hastada $12 \mathrm{iyi} /$ mükemmel sonuç elde etmiş ve 12 hastada kaynama sağlamışlardır. Sadece bir hastada revizyon cerrahisi gerekmiştir. Ortalama öne fleksiyon derecesini de $144^{\circ}$ olarak bildirmişlerdir. ${ }^{[33]}$
Badman ve ark., 2006 yılında yeni bir cerrahi teknik yayımlamışlardır. ${ }^{[34]} \mathrm{Bu}$ teknikte, anatomik sabit açılı kilitli plak ve intramedüller fibula strut allogrefti uygulamışlardır. Allogreft kullanımı ile, hem mekanik destek sağlanmış hem de otogreftteki donör saha morbiditesi ortadan kaldırılmıştır. Bu cerrahi tekniği kullandıkları 18 hastanın 17'sinde, ortalama 5,4 ayda kaynama elde etmişlerdir. Ortalama öne fleksiyonu $115^{\circ}$ ve ortalama ASES skorunu 81 olarak bildirmişlerdir. ${ }^{[35]}$ 
Allende ve ark. 2008 yilında, $90^{\circ}$ kama plak ve grefonaj ile yedi hastanın hepsinde de kaynama elde ettiklerini bildirmişlerdir. Ortalama kaynama süresi 5,9 ay ve ortalama Constant skoru 72,7 olarak bulunmuştur. ${ }^{[36]}$ Aynı yıl Yamane ve ark., kilitli intramedüller çivi ve kemik grefti uyguladıkları 13 hastanın tamamında kaynama elde ettiklerini bildirmişlerdir. On üç hastanın 11'inde iyi veya mükemmel sonuç elde ettiklerini ve ortalama öne fleksiyon derecesini $122^{\circ}$ olarak bildirmişlerdir. ${ }^{[37]}$

Tauber ve ark. 2011 yılında yayımladıkları araştırmada, önceki yayınlardan farklı olarak kemik grefti kullanmamışlardır. Kırk beş hastada kama plak ve 10 hastada 'humerusblock device' ile, greft kullanmadan \%93'lük bir kaynama elde etmişlerdir. Ortalama Constant skoru 83,2 ve ortalama öne fleksiyon $138^{\circ}$ olarak bildirilmiştir. Sekiz hastada komplikasyonla (dört implant kaynaklı, iki avasküler nekroz, iki enfeksiyon) karşılaşmışlardır ve beş hastada revizyon yapılması gerekmiştir. ${ }^{[38]}$ Quadlbauer ve ark. da 2017 yılında, benzer bir şekilde, greft kullanmadan kilitli sabit açılı plak ile tespit sonuçlarını bildirmişlerdir. Dokuz hastanın tamamında atrofik kaynamama olmasına rağmen greft kullanmadan tamamında kaynama elde etmişlerdir. Ortalama öne fleksiyon $136^{\circ}$ olarak bildirilmiştir. ${ }^{[39]}$

\section{ARTROPLASTI SONUÇLARI}

Nayak ve ark. 1995 yılında, hemiartroplasti uyguladıkları yedi hastada ağrı kontrolünün sağlandığını, hastalarda günlük aktivitelerini yerine getirebilecek kadar fonksiyonel iyileşme sağlandığını, ancak hiçbir hastanın yaralanma öncesi seviyesine dönemediğini bildirmişlerdir. ${ }^{[24]}$

Antuna ve ark. 2002 yılında, artroplasti uyguladıkları 25 hastalık serilerini yayımlamışlardır. ${ }^{[14]}$ Yirmi bir hastada hemiartroplasti, dört hastada total artroplasti uygulamış, 12 hastada mükemmel veya tatmin edici sonuç elde etmiş̧lerdir. Hastalarda ağrı kontrol altına alınmış, ancak fonksiyonel iyileşme beklendiği kadar elde edilememiştir. Osteoartrit endikasyonu ile yapılan primer artroplasti sonuçlarına göre, fonksiyonel sonuçlar yetersiz kalmıştır. Hastaların ortalama öne fleksiyonu $88^{\circ}$ olarak bildirilmiştir. On bir hastada, büyük tüberkül ya rezorbe olmuş ya da kaynamamıştır. Bu durum da fonksiyonel sonuçların neden yetersiz olduğunu açıklamaktadır.

Boileau ve ark. 2006 yılında, 203 artroplasti hastasını inceleyerek humerus proksimal kırıklarının sekelleri için bir radyolojik sınıflama sistemi oluşturmuş ve bu sistemi kullanarak omuz artroplastisi için endikasyonları belirlemişlerdir. Bu sınıflamada, cerrahi boyun kaynamamaları ekstrakapsüler Tip 3 lezyon olarak belirlenmiştir. Anatomik omuz artroplastisi yapılan Tip 3 lezyonlarda, tatmin edici olmayan sonuçlar ve yüksek komplikasyon oranı (\%32) bildirilmiştir. Bu tip lezyonlar, anatomik omuz artroplastisi için göreceli kontrendikasyon olarak belirlenmiş̧ir. Aynı çalışmada, tüberkül malunion'u bulunan Tip 4 lezyonlar için ters total omuz protezi yapılmasını önermişlerdir. ${ }^{\left[{ }^{[0]}\right.}$

Duquin ve ark. 2012 yılında, 67 hastada uyguladıkları artroplasti sonuçlarını bildirmişlerdir. ${ }^{[41]}$ Elli dört hastaya hemiartroplasti, 13 hastaya da total artroplasti yapılmıştır. Hastaların ağrılarında belirgin azalma ve fonksiyonlarında iyileşme olmasına rağmen, \%50'sinden fazlası ortalama dokuz yıllık takip sonrası sonuçlardan tatmin olmamıştır. Ortalama öne fleksiyon $104^{\circ}$ olarak bildirilmiştir. Komplikasyon oranı $\% 21$ ve tekrar ameliyat oranı \%18 olarak belirtilmiştir. Tüberküllerin anatomik veya anatomiye yakın kaynamasının, aktif öne fleksiyonu etkileyen en önemli faktör olduğunu bildirmişlerdir.

Aynı yıl Martinez ve ark., yaş ortalaması 78,8 olan 18 hastada ters omuz protezi sonuçlarını bildirmişlerdir. Ortalama öne fleksiyon $90^{\circ}$ ve 18 hastanın 14'ünün fonksiyonel sonuçlardan tatmin olduğu bildirilmiştir. Ancak, komplikasyon oranı \%27, reoperasyon oranı \%22 olarak tespit edilmiştir. İki hastada dislokasyon görülmüş ve bu sorun glenosferin daha büyük boyu (42 mm) ile değiştirilmesi ile ortadan kaldırılmıştır. ${ }^{[42]}$

Walch ve ark. 2014 yılında yaptıkları çalışmada, 32 hastada ters omuz protezi sonuçlarını bildirmişlerdir. ${ }^{[43]}$ Yaş ortalaması 68 olan ve ortalama dört yıl takip edilen hastaların fonksiyonel skorlarında ve hareket açıklığında belirgin düzelme tespit edilmiştir. Ortalama fleksiyon 109,7 olarak bildirilmiştir. Ancak, komplikasyon oranı \%41 ve reoperasyon oranı \%28 gibi yüksek oranlarda bulunmuştur. En sık görülen komplikasyon, \%34 ile dislokasyon olarak bildirilmiştir. Dislokasyon riskini arttıran en önemli faktörün tüberküllerin rezeksiyonu olduğu ve dislokasyon riskini azaltmak için tüberküllerin korunması gerektiği bildirilmiştir. Aynı yıl içinde Zafra ve ark., yayımladıkları 35 hastalık ters omuz protezi serisinde, ortalama öne fleksiyonu $116,7^{\circ}$ bulmuş ve hastaların ikisi hariç hepsinin daha iyi hissettiğini bildirmişlerdir. Ancak, bu seride de komplikasyon oranı \%20, dislokasyon oranı $\% 17$ gibi yüksek seviyelerde bulunmuştur. ${ }^{[44]}$

\section{SONUÇ}

Proksimal humerus bölgesi spongiyöz kemikten oluşsa da, bu bölgenin kırıklarında önemli oranda kaynamama görülmektedir. Doğru değerlendirme neticesinde, hastanın kemik kalitesine ve kaynamama tipine göre tedavi yöntemi belirlenir. Kaynamamanın nedeni 
eğer mekanik eksiklik ise ve proksimal parçada yeteri kadar kaliteli kemik varsa, greft ile desteklenen osteosentez tercih edilmektedir. Eğer baş parçada yeteri kadar canlı kemik bulunmazsa artroplasti seçenekleri gündeme gelir.

\section{KAYNAKLAR}

1. Handoll HH, Gibson JN, Madhok R. Interventions for treating proximal humeral fractures in adults. Cochrane Database Syst Rev 2003;(4):CD000434. Crossref

2. Neer CS, 2nd. Displaced proximal humeral fractures. I. Classification and evaluation. J Bone Joint Surg Am 1970;52(6):1077-89.

3. Tepass A, Blumenstock G, Weise K, Rolauffs B, Bahrs C. Current strategies for the treatment of proximal humeral fractures: an analysis of a survey carried out at 348 hospitals in Germany, Austria, and Switzerland. J Shoulder Elbow Surg 2013;22(1):e8-14. Crossref

4. Sanders RJ, Thissen LG, Teepen JC, van Kampen A, Jaarsma RL. Locking plate versus nonsurgical treatment for proximal humeral fractures: better midterm outcome with nonsurgical treatment. J Shoulder Elbow Surg 2011;20(7):1118-24. Crossref

5. Konrad G, Audige L, Lambert S, Hertel R, Sudkamp NP. Similar outcomes for nail versus plate fixation of threepart proximal humeral fractures. Clin Orthop Relat Res 2012;470(2):602-9. Crossref

6. Haasters F, Siebenburger $G$, Helfen $T$, Daferner M, Bocker W, Ockert B. Complications of locked plating for proximal humeral fractures-are we getting any better? J Shoulder Elbow Surg 2016;25(10):e295-303. Crossref

7. Roux A, Decroocq L, El Batti S, Bonnevialle N, Moineau G, Trojani C, Boileau P, de Peretti F. Epidemiology of proximal humerus fractures managed in a trauma center. Orthop Traumatol Surg Res 2012;98(6):715-9. Crossref

8. Warner JP, Costouros JG, Gerber C. Fractures of the proximal humerus. In: Bucholz RW, Heckman JD, Court-Brown C, editors. Rockwood and Green's Fractures in Adults, 6th ed. Philadelphia: Lippincott Williams \& Wilkins; 2006. pp.1161-210.

9. Neer CS, 2nd. Displaced proximal humeral fractures. II. Treatment of three-part and four-part displacement. J Bone Joint Surg Am 1970;52(6):1090-103.

10. Court-Brown CM, McQueen MM. Nonunions of the proximal humerus: their prevalence and functional outcome. J Trauma 2008;64(6):1517-21. Crossref

11. Hanson B, Neidenbach $P$, de Boer $P$, Stengel D. Functional outcomes after nonoperative management of fractures of the proximal humerus. J Shoulder Elbow Surg 2009;18(4):61221. Crossref

12. Clavert P, Adam P, Bevort A, Bonnomet F, Kempf JF. Pitfalls and complications with locking plate for proximal humerus fracture. J Shoulder Elbow Surg 2010;19(4):489-94. Crossref

13. Galatz LM, lannotti JP. Management of surgical neck nonunions. Orthop Clin North Am 2000;31(1):51-61.

14. Antuña SA, Sperling JW, Sanchez-Sotelo J, Cofield RH. Shoulder arthroplasty for proximal humeral nonunions. J Shoulder Elbow Surg 2002;11(2):114-21.

15. Healy WL, Jupiter JB, Kristiansen TK, White RR. Nonunion of the proximal humerus. A review of 25 cases. J Orthop Trauma 1990;4(4):424-31.
16. Checchia SL, Doneux P, Miyazaki AN, Spir IA, Bringel R, Ramos $\mathrm{CH}$. Classification of non-unions of the proximal humerus. Int Orthop 2000;24(4):217-20.

17. Duralde XA, Flatow EL, Pollock RG, Nicholson GP, Self $\mathrm{EB}$, Bigliani LU. Operative treatment of nonunions of the surgical neck of the humerus. J Shoulder Elbow Surg 1996;5(3):169-80.

18. Jung WB, Moon ES, Kim SK, Kovacevic D, Kim MS. Does medial support decrease major complications of unstable proximal humerus fractures treated with locking plate? BMC Musculoskelet Disord 2013;14:102. Crossref

19. Klement MR, Nickel BT, Bala A, Penrose CT, Zura RD, Garrigues GE. Glenohumeral arthritis as a risk factor for proximal humerus nonunion. Injury 2016;47 Suppl 7:S36-9. Crossref

20. Padegimas EM, Zmistowski B, Lawrence C, Palmquist A, Nicholson TA, Namdari S. Defining optimal calcar screw positioning in proximal humerus fracture fixation. J Shoulder Elbow Surg 2017;26(11):1931-7. Crossref

21. Schnetzke M, Bockmeyer J, Porschke F, Studier-Fischer S, Grützner PA, Guehring T. Quality of Reduction Influences Outcome After Locked-Plate Fixation of Proximal Humeral Type-C Fractures. J Bone Joint Surg Am 2016;98(21):177785. Crossref

22. Cadet ER, Yin B, Schulz B, Ahmad CS, Rosenwasser MP. Proximal humerus and humeral shaft nonunions. J Am Acad Orthop Surg 2013;21(9):538-47. Crossref

23. Papakonstantinou MK, Hart MJ, Farrugia R, Gosling C, Kamali Moaveni A, van Bavel D, Page RS, Richardson MD. Prevalence of non-union and delayed union in proximal humeral fractures. ANZ J Surg 2017;87(1-2):55-9. Crossref

24. Nayak NK, Schickendantz MS, Regan WD, Hawkins RJ. Operative treatment of nonunion of surgical neck fractures of the humerus. Clin Orthop Relat Res 1995;(313):200-5.

25. Checchia SL, Miyazaki AN, Fregoneze M, Santos PD, da Silva LA, Nascimento LG. Pseudarthrosis of the humeral neck: analysis of the results when using the technique described by Walch, et al. Rev Bras Ortop 2009;44(3):239-46. Crossref

26. Cheung EV, Sperling JW. Management of proximal humeral nonunions and malunions. Orthop Clin North Am 2008;39(4):475-82, vii. Crossref

27. Newman JT, Stahel PF, Smith WR, Resende GV, Hak DJ, Morgan SJ. A new minimally invasive technique for large volume bone graft harvest for treatment of fracture nonunions. Orthopedics 2008;31(3):257-61.

28. Kanakaris NK, Morell D, Gudipati S, Britten S, Giannoudis PV. Reaming Irrigator Aspirator system: early experience of its multipurpose use. Injury 2011;42 Suppl 4:S28-34. Crossref

29. Cox G, Jones E, McGonagle D, Giannoudis PV. Reamerirrigator-aspirator indications and clinical results: a systematic review. Int Orthop 2011;35(7):951-6. Crossref

30. Walch G, Badet R, Nove-Josserand L, Levigne C. Nonunions of the surgical neck of the humerus: surgical treatment with an intramedullary bone peg, internal fixation, and cancellous bone grafting. J Shoulder Elbow Surg 1996;5(3):161-8.

31. Ring D, McKee MD, Perey BH, Jupiter JB. The use of a blade plate and autogenous cancellous bone graft in the treatment of ununited fractures of the proximal humerus. J Shoulder Elbow Surg 2001;10(6):501-7. Crossref

32. Lin J, Hou SM. Locked-nail treatment of humeral surgical neck nonunions. J Trauma 2003;54(3):530-5. Crossref

33. Galatz LM, Williams GR Jr, Fenlin JM Jr, Ramsey ML, Iannotti JP. Outcome of open reduction and internal fixation of surgical neck nonunions of the humerus. J Orthop Trauma 2004;18(2):63-7. 
34. Badman BL, Mighell M, Drake GN. Proximal humeral nonunions: Surgical technique with fibular strut allograft and fixed-angle locked plating. Tech Shoulder Elbow Surg 2006;7(2):95-101.

35. Badman BL, Mighell M, Kalandiak SP, Prasam M. Proximal humeral nonunions treated with fixed-angle locked plating and an intramedullary strut allograft. J Orthop Trauma 2009;23(3):173-9. Crossref

36. Allende C, Allende BT. The use of a new locking 90 degree blade plate in the treatment of atrophic proximal humerus nonunions. Int Orthop 2009;33(6):1649-54. Crossref

37. Yamane S, Suenaga N, Oizumi N, Minami A. Interlocking intramedullary nailing for nonunion of the proximal humerus with the Straight Nail System. J Shoulder Elbow Surg 2008;17(5):755-9. Crossref

38. Tauber $M$, Brugger $A$, Povacz $P$, Resch $H$. Reconstructive surgical treatment without bone grafting in nonunions of humeral surgical neck fractures. J Orthop Trauma 2011;25(7):392-8. Crossref

39. Quadlbauer S, Hofmann GJ, Leixnering M, Rosenauer R, Hausner T, Reichetseder J. Open reduction and fixation with a locking plate without bone grafting is a reasonable and safe option for treating proximal humerus nonunion. Int Orthop 2018. Crossref
40. Boileau P, Chuinard C, Le Huec JC, Walch G, Trojani C. Proximal humerus fracture sequelae: impact of a new radiographic classification on arthroplasty. Clin Orthop Relat Res 2006;442:121-30.

41. Duquin TR, Jacobson JA, Sanchez-Sotelo J, Sperling JW, Cofield RH. Unconstrained shoulder arthroplasty for treatment of proximal humeral nonunions. J Bone Joint Surg Am 2012;94(17):1610-7. Crossref

42. Martinez AA, Bejarano C, Carbonel I, Iglesias D, Gil-Albarova $J$, Herrera $A$. The treatment of proximal humerus nonunions in older patients with reverse shoulder arthroplasty. Injury 2012;43 Suppl 2:S3-6. Crossref

43. Raiss P, Edwards TB, da Silva MR, Bruckner T, Loew M, Walch G. Reverse shoulder arthroplasty for the treatment of nonunions of the surgical neck of the proximal part of the humerus (type-3 fracture sequelae). J Bone Joint Surg Am 2014;96(24):2070-6. Crossref

44. Zafra M, Uceda P, Flores M, Carpintero P. Reverse total shoulder replacement for nonunion of a fracture of the proximal humerus. Bone Joint J 2014;96-B(9):1239-43. Crossref 